\title{
Gender Differences in Job Entry Decisions: A University-Wide Field Experiment
}

\author{
Anya Samek* \\ University of Southern California
}

November, 2014

This Version: September 17, 2015

\begin{abstract}
The gender difference in competitiveness has been cited as an important factor driving the gender gap in labor market outcomes. Using a natural field experiment with 35,000 university students, I explore the impact of compensation scheme on willingness to apply for a job. I find that competitive compensation schemes disproportionately deter women from applying, which cannot be explained by differences in risk preferences alone. I also vary whether the job is introduced as helping a non-profit, which increases application rates, suggesting a role for social preferences in application decisions. Finally, I observe a correlation between competitiveness preferences and career choice.
\end{abstract}

JEL classification: C93 J23 J33

Keywords: field experiment, gender, competitiveness, labor market

*Anya Savikhin Samek, University of Southern California, Center for Economic and Social Research, 635 Downey Way, Los Angeles CA 90089; anyasamek@gmail.com. This research was funded by the BRITE Laboratory at the University of Wisconsin-Madison and by the Science of Philanthropy Initiative through a grant from the John Templeton Foundation. I thank Judd Kessler, Jonathan Meer, Gary Charness, Ragan Petrie, Catherine Eckel, Lise Vesterlund, John List, Alex Imas, faculty at George Mason University, participants at the University of Southern California Center for Economic and Social Research seminar series, and participants at the Economic Science Association Meetings for helpful comments. I thank Christa Gibbs and Charis Li for excellent research assistance. I also thank the University of Wisconsin-Madison Division of Information Technology and my Behavioral and Experimental Economics (BEE) student group, including Kevin Huang, Daniel Li, Dustin Pashouwer, Carrie Ip, Wanqun Zhao, Lynn Lin, Peitong Jing, Tristan Abbott, Annelise Ross, and Ziqi Zhao for their hard work in helping carry out this project. 


\section{Introduction}

While women in many developed countries are pursuing higher education at similar rates as men, women continue to have relatively lower earnings and are significantly less likely to hold executive positions in firms. In the United States, this gender gap amounts to an earning rate of women that is $79 \%$ of men's. The earnings gap in other developed countries is similar, ranging from $75 \%$ (Austria) to $95 \%$ (Italy). ${ }^{1}$ As noted by Bertrand (2009), women account for only 1-2.5\% of the highest paid executives in the U.S. Proposed reasons for the earnings gap include differences in human capital, discrimination and stereotypes against women, and differences in time taken out of the labor force (Blau and Kahn, 1992; Waldfogel, 1998). More recently, gender differences in preferences, specifically preferences for competition, have been proposed as an important reason for the gender gap (Niederle and Vesterlund, 2011). Competitiveness preferences are important because they may not only affect the job entry decision, but also the choice to compete for promotions and the decision to negotiate salary (Leibbrandt and List, 2014; Dittrich, Knabe and Leipold, 2014).

A large literature uses laboratory experiments to find support for the competitiveness gap by demonstrating that men prefer to compete while women shy away from competition (Niederle and Vesterlund, 2011). Seminal work includes Gneezy, Niederle and Rustichini (2003), who find that as the competitiveness of the environment is increased, the performance of men improves while the performance of women does not. Niederle and Vesterlund (2007) find that twice as many men as women choose to enter a tournament in the laboratory, despite no difference in performance. The gender gap in competitiveness is even observed among children (Gneezy and Rustichini, 2004; Cardenas, Dreber, Von Essen and Ranehill, 2012; Andersen, Ertac, Gneezy, List and Maximiano, 2013; Samak, 2013; Sutter and Glätzle-Rützler, 2014).

Identifying the role that competitiveness plays in job entry decisions in naturally occurring labor markets is key to our understanding of gender disparities. Yet field evidence for the competitiveness result is limited, with two notable exceptions. Flory, Leibbrandt and List (2014) conducted a field experiment in which online job seekers were randomized to one of several compensation schemes, including a competitive and flat rate compensation. Flory et al. (2014) found that both men and women shy away from competition, but that women do so at higher rates. Buser, Niederle and Oosterbeek (2014) conducted experiments with school-children and found that competitiveness elicited in the laboratory is predictive of subsequent career decisions. ${ }^{2}$

\footnotetext{
${ }^{1}$ Data from the U.S. Census and the Social Situation in the European Union Report.

${ }^{2}$ In a related field experiment, Lavy (2013) explores performance (rather than job entry decisions)
} 
My contribution is to provide field evidence for the gender gap in competitiveness using a large-scale natural field experiment with over 35,000 university students. By randomizing potential job applicants to different compensation schemes, I directly identify the effects of performance pay and other job characteristics on the willingness to apply for the job. Importantly, I also control directly for risk preferences over earnings, going beyond Flory et al. (2014), whose risk preference treatment is not designed to separately identify risk preferences from confidence in performance or ambiguity preferences. ${ }^{3}$ Complementing the work of Buser et al. (2014), I also explore whether career choice (measured by major at the university) is correlated with the willingness to compete. Following the methodology of the 'natural field experiment,' students were observed in their natural environment and were not told that they were participating in an experiment (Harrison and List, 2004). Administrative data from the university allows me to perfectly identify the gender of each e-mail recipient, without ever asking about gender directly.

In addition to documenting the gender gap in competitiveness, researchers have explored ways to mitigate its effect in the labor market. Institutional changes, such as affirmative action or quotas favoring women, increase the propensity of women to compete (Niederle, Segal and Vesterlund, 2013; Balafoutas and Sutter, 2010). The gap is also reduced for team competition (Healy and Pate, 2011; Kuhn and Villeval, 2011; Dargnies, 2012; Flory et al., 2014), when information about other applicants is made available (Gee, 2014) and through feedback (Wozniak, Harbaugh and Mayr, 2009).

One manipulation that has remained unexplored is incorporating a concern for others (social preferences) into the information received prior to the decision to compete. Harnessing social preference concerns may be a promising new approach to reducing the gender gap, since related work finds that individuals who are more competitive are less pro-social, and vice versa (Bartling, Fehr, Maréchal and Schunk, 2009; Savikhin and Sheremeta, 2013). While some studies find that women are more prosocial than men (Eckel and Grossman, 1998; Einolf, 2011), others find no or mixed evidence of a gender difference (Andreoni and Vesterlund, 2001; Bolton and Katok, 1995; Ben-Ner, Kong and Putterman, 2004). More generally, the impact of social preferences on job

among school-teachers assigned to a competition, and does not find gender differences. However, the author concludes that care should be taken in interpreting the results due to possible differences in sorting. Another experiment in the field is Gneezy, Leonard and List (2009), who conduct artefactual field experiments with subjects from patriarchal and matriarchal societies.

${ }^{3}$ There are additional differences in the environment and subject pool between my work and Flory et al. (2014). While Flory et al. (2014) uses a pool of subjects who on average have an associate's degree, my subjects are university students generally on track to receive a bachelor's degree and join the high-skilled workforce. My pool also includes graduate students pursuing advanced degrees. 
entry decisions is an open question; this is the first investigation that I know of that considers whether a non-profit manipulation affects the job entry decision.

In the experiment, students received one of several different e-mails advertising an opening for a short-term job. To identify the roles of competitiveness and risk preferences on the decision to apply, I varied whether the compensation scheme for the project was (1) flat rate, (2) competitive, performance-based bonus or (3) bonus not based on performance. To learn if social preferences narrow the competitiveness gap in the labor market, in my experiment I also varied whether or not the job was described as helping a charity. The charity manipulation was conducted for both the flat and performance-based compensation schemes. If women are more likely than men to respond positively to the charity frame by applying for the job, this social preference manipulation could reduce the gender gap in worker entry in competitive environments. Moreover, if pro-sociality is negatively correlated with competitiveness, then the charity framing should have the largest effect on those who are the least competitive, exactly what may be needed to reduce the gender gap in earnings.

I find that competitive, performance based compensation schemes deter workers of both genders from applying, but that the effect is larger and statistically significant for women. The effect cannot be explained by differences in risk preferences alone. I also vary whether the job is introduced as a non-profit, and find that this manipulation increases application rates, especially under the tournament compensation scheme, suggesting a role for social preferences in the decision to apply. The willingness to compete is mediated by career choice, whereby the students from the Business and Engineering schools actually seem to prefer competition. Finally, I find suggestive evidence that the gap in competitiveness is reduced in the non-profit frame. My results add to our understanding of how economic preferences affect job entry decisions, and their effects on the gender gap in labor market earnings.

In what follows, Section 2 outlines the procedures and design of the experiment. Section 3 summarizes the findings. Section 4 provides a discussion and concludes.

\section{The Experiment}

\section{$2.1 \quad$ Procedures}

The experiment was designed to measure willingness to apply for jobs with different compensation schemes and characteristics. 35,462 University of Wisconsin-Madison undergraduate and graduate students were stratified by gender and school using ad- 
ministrative data and randomized to one of five different treatments that varied the compensation scheme and the characteristics of the job. Then, each student was sent an e-mail offering temporary student employment. The email stated, "We are seeking temporary student help in the next two weeks to assist with preparing materials for several projects."

The e-mails, available in Appendix A, specified that multiple, two-hour time slots were available in the following week (including days, evenings and weekends) and that special training was not required in order to apply. The e-mails also specified that work would be completed individually. To avoid introducing gender bias in the job description, the e-mails were vague regarding the specifics of the assignment and were sent from one of my project assistants with a unisex name, Chris Gibbs. ${ }^{4}$

Students were invited to apply for the position by responding to the email and including 1) their major and year at university, 2) the number of course credits they are currently taking and 3) a list of shifts they willing to work. The e-mail specified that signing up for more shifts increases the probability of being invited to do the job, but that each student would only be assigned to work one shift. Importantly, since the number of shifts selected was positively related to the likelihood of being hired, I am able to use the number of shifts applied for as a clear measure of the individual's interest in the job.

The main outcome measures were the application rate and the application effort. The application rate is the total number of applicants divided by the total number of e-mails sent out. ${ }^{5}$ The application effort is measured by willingness to apply to up to 56 different possible shifts, provided in the e-mail. Application effort can be considered both the time spent typing out (or copying and pasting) a larger number of shifts in the e-mail, as well as the willingness to work during progressively less desirable shifts.

Many of the applicants - over 400 - were subsequently actually hired to work for our research group. While not all applicants could be hired due to need or space limitations, as stated in the e-mail, the likelihood of being hired was positively related to the number of shifts the student selected. Workers received a short training and then worked individually in an office stuffing envelopes that were part of several mailing campaigns for a charity. In section 3.6, I also investigate gender differences in worker performance on the job.

\footnotetext{
${ }^{4}$ Responses suggested that at least some students were indeed unaware of the gender of the employer, with some students addressing us as 'Mrs.' or 'Ms.' and others as 'Mr.' Gibbs in their response.

${ }^{5}$ Since all e-mails used are official university e-mails, all e-mails were accurate and belonged to a current student at the university.
} 


\subsection{Experimental Treatments}

Table 1 provides a summary of treatments implemented in the experiment, with the number of students e-mailed, by treatment. Treatments differed first in the offered compensation scheme. Students assigned to Flat Rate compensation scheme were offered $\$ 24$ for their 2-hour shift ( $\$ 12$ per hour). Students assigned to a Tournament scheme were told that they would receive $\$ 18$ for their 2-hour shift ( $\$ 9$ per hour) but also have the opportunity to earn a bonus of $\$ 12$, based on their performance. At the end of the shift, their work would be compared to one other worker, and the worker who did better would receive the bonus. As compared to the Flat Rate treatments, the Tournament treatments introduced uncertainty in payoffs, which was linked to one's individual performance relative to another worker. Thus, comparisons of application rates by compensation scheme and gender provide a measure of preference for competition.

The Tournament differs from the Flat Rate both in the level of uncertainty in earnings and in relative performance. Related work also finds gender differences in risk preferences - when money is at stake, women are significantly less likely to take risks than men (Charness and Gneezy, 2012; Eckel and Grossman, 2008). In Flory et al. (2014) applicants in the risk preference treatment are told that their earnings would be based on whether their effort ends up contributing to journal article publications. This manipulation incorporates an ambiguity component and also involves some measure of confidence in performance. My contribution is a Bonus compensation scheme to separately identify the effect of risk preferences over earnings on the gender gap. Students assigned to the Bonus compensation scheme were told that they would receive $\$ 18$ for their 2-hour shift with a $50 \%$ chance of a $\$ 12$ bonus, as in the Tournament treatment. However, in the Bonus scheme the $\$ 12$ bonus was not tied to performance and was determined at random (by spinning a 'bonus wheel'). Comparisons of application rates by gender in Bonus and Flat Rate provide insights into whether and how possible gender differences in risk preferences translate to the labor market. Comparisons of application rates by gender in Bonus as compared to Tournament allow me to measure whether differences in risk preferences alone can explain the gender gap in competitiveness.

Finally, treatments varied in how the e-mail specified the purpose of the work. Prior to describing the compensation scheme, the Baseline e-mail stated simply that 'The materials for this project are very important.' In the Non-Profit treatments, the e-mail stated that 'The materials for this project are for a charity drive for a non-profit and are very important.' Both the Baseline and Non-Profit wording was tested with the 
Flat Rate and Tournament compensation schemes. ${ }^{6}$

In the Baseline treatments, the utility gain from working is in the form of a private benefit (being paid). In the Non-Profit treatments, if individuals have pro-social preferences, there will be an additional utility gain from working. Altruistic individuals will receive utility from work that increases the welfare of others, and individuals motivated by 'warm glow' will receive utility from the act of working for charity itself (Andreoni, 1990, 1989). Evidence for benefits of pro-social incentives are reported by Imas (2014), who finds that in some settings in the laboratory, individuals work harder when benefits accrue to a charity than when they accrue to themselves. A similar result is observed in the online experiment of Tonin and Vlassopoulos (2014), who compare productivity where benefits from a real effort task accrue either to the worker or to a charity, and Charness, Cobo-Reyes and Sanchez (2014), who find that workers are motivated to stay in the lab longer when their effort benefits charity. Relatedly, Brown, Meer and Williams (2013) find that people are willing to work when payment accrues to charity.

The expected payoff under Flat Rate and Bonus compensation schemes was $\$ 24$. The expected payoff in Tournament was also $\$ 24$ assuming no over- or under-confidence in ability. While related laboratory experiments identify social preferences by having output accrue to charity directly (Imas, 2014; Tonin and Vlassopoulos, 2014; Charness et al., 2014), in my field experiment such a manipulation may seem unnatural to potential job seekers and therefore in all cases the earnings accrued to the individual. Instead, the subtle information about the non-profit was used to induce a pro-social incentive. For those who worked, the earnings were paid out in cash at the end of the 2-hour shift.

Table 1: Summary of Experiment

\begin{tabular}{|l|l|l|l|}
\hline & Flat Rate & Tournament & Bonus \\
\hline \multirow{2}{*}{ Baseline } & $\mathrm{N}=7,093$ & $\mathrm{~N}=7,093$ & $\mathrm{~N}=7,093$ \\
& $50.7 \%$ women & $50.7 \%$ women & $50.7 \%$ women \\
\hline \multirow{2}{*}{ Non-Profit } & $\mathrm{N}=7,090$ & $\mathrm{~N}=7,093$ & \\
& $50.7 \%$ women & $50.7 \%$ women & \\
\hline
\end{tabular}

\footnotetext{
${ }^{6}$ The Non-Profit treatment with the Bonus compensation scheme was not implemented.
} 


\section{Results}

\section{$3.1 \quad$ Overview}

Overall, $1.38 \%$ of e-mail recipients applied for the job, which represents $1.95 \%$ of all female students and $0.80 \%$ of all male students. In total, there were 491 applicants. Notice that the application rate for females was significantly higher than that of males (Pearson $\chi^{2}$ test $p<0.01$ for both the full sample and the Flat Rate treatment sample). It is possible that the job description 'preparing materials' was more attractive to female students, or that female students are in general more likely to apply for oncampus jobs like the one I advertised. The larger overall response rate by women is also observed by Flory et al. (2014), for a job described as office support. One caveat is that the job may only appeal to a certain 'type' of individual, so that response rates are not representative for 'any' job. The average number of shifts applied for across all treatments, conditional on applying, was $11.64(s . d .=9.07)$. Women selected an average of $11.31(s . d .=8.87)$ while men selected an average of $12.45(s . d .=9.52)$ shifts, with no statistically significant difference in effort conditional on applying by gender (Mann-Whitney $p>0.10$ ).

Table 2 provides a summary of the application probability (measured as the number of students who applied divided by number who were e-mailed) and application effort (measured by number of shifts selected) by treatment and gender (standard error in parentheses). Conditional application effort is the number of shifts selected, conditional on applying; while unconditional application effort is the number of shifts selected overall, treating non-applicants as 0 .

Some general patterns emerge. First, the overall application rate is significantly higher in Flat Rate $(1.48 \%)$ versus Tournament $(0.87 \%)$, suggesting that individuals shy away from competition ( $\chi^{2}$ test $p<0.01$ when comparing Flat Rate and Tournament). Second, the main driver of the reduction in applications does not seem to be uncertainty in earnings, since the Bonus treatment results in the same number of applications (1.48\%) as the Flat Rate treatment. Finally, identifying the purpose of the job as helping a charity increases the likelihood of applying under both flat rate and tournament compensation schemes (1.75\% and $1.25 \%$, respectively), suggesting a role for social preferences in the motivation to apply for the job. This difference is statistically significant for Tournament treatments $\left(\chi^{2}\right.$ test $p<0.05$ when comparing Tournament to Non-Profit Tournament) but not for Flat Rate treatments ( $\chi^{2}$ test $p=0.16$ when comparing Flat Rate to Non-Profit Flat Rate). Interestingly, among women, effort conditional on applying decreases between Flat Rate and Tournament; 
whereas among men, effort conditional on applying increases between Flat Rate and Tournament.

Table 2: Summary Statistics

\begin{tabular}{|c|c|c|c|c|c|c|c|c|}
\hline & \multicolumn{4}{|c|}{ Females } & \multicolumn{4}{|c|}{ Males } \\
\hline & $\% A p p$ & $\begin{array}{l}\text { Effort } \\
\text { Cond. }\end{array}$ & Effort & $\mathrm{N}$ & $\% A p p$ & $\begin{array}{l}\text { Cond. } \\
\text { Effort }\end{array}$ & Effort & $\mathrm{N}$ \\
\hline Flat Rate & $2.19 \%$ & $\begin{array}{l}12.57 \\
(1.02)\end{array}$ & $\begin{array}{c}0.28 \\
(0.04)\end{array}$ & 3,594 & $0.74 \%$ & $\begin{array}{l}11.15 \\
(1.66)\end{array}$ & $\begin{array}{c}0.08 \\
(0.02)\end{array}$ & 3,499 \\
\hline Tournament & $1.19 \%$ & $\begin{array}{l}10.67 \\
(0.92)\end{array}$ & $\begin{array}{c}0.13 \\
(0.03)\end{array}$ & 3,594 & $0.54 \%$ & $\begin{array}{l}12.89 \\
(1.66)\end{array}$ & $\begin{array}{c}0.07 \\
(0.02)\end{array}$ & 3,499 \\
\hline Bonus & $2.09 \%$ & $\begin{array}{l}12.35 \\
(1.09)\end{array}$ & $\begin{array}{c}0.26 \\
(0.04)\end{array}$ & 3,594 & $0.86 \%$ & $\begin{array}{l}12.60 \\
(1.39)\end{array}$ & $\begin{array}{c}0.11 \\
(0.02)\end{array}$ & 3,499 \\
\hline $\begin{array}{l}\text { Non-Profit } \\
\text { Flat }\end{array}$ & $2.50 \%$ & $\begin{array}{l}10.59 \\
(0.92)\end{array}$ & $\begin{array}{c}0.27 \\
(0.04)\end{array}$ & 3,593 & $1.03 \%$ & $\begin{array}{l}12.14 \\
(1.79)\end{array}$ & $\begin{array}{c}0.12 \\
(0.03)\end{array}$ & 3,500 \\
\hline $\begin{array}{l}\text { Non-Profit } \\
\text { Tournament }\end{array}$ & $1.75 \%$ & $\begin{array}{c}9.97 \\
(0.81)\end{array}$ & $\begin{array}{c}0.17 \\
(0.03)\end{array}$ & 3,593 & $0.74 \%$ & $\begin{array}{l}14.27 \\
(2.48)\end{array}$ & $\begin{array}{c}0.11 \\
(0.03)\end{array}$ & 3,500 \\
\hline
\end{tabular}

\subsection{Gender Differences in Competitiveness}

Due to gender differences in underlying preferences for the job reported in section 3.1, I first compare differences in application rates for each treatment by gender. As Table 2 shows, the application rate of women is lower by $45.67 \%$ in Tournament relative to Flat Rate, while the application rate of men is lower by $26.9 \%$ in Tournament. This represents a significant decrease in application rates for women $\left(\chi^{2}\right.$ test $\left.p<0.01\right)$ but not for men $\left(\chi^{2}\right.$ test $\left.p>0.30\right)$. Application effort is another possible outcome measure; again, I observe a significant decrease for women (from 0.28 to 0.13, Mann-Whitney $p<0.01$ ) but not for men (from 0.08 to $0.07, p=0.30$ ). ${ }^{7}$

Table 3 reports regressions of treatment dummies, gender and treatment-gender interactions on the decision to apply for the job (the non-profit treatments are excluded as they are discussed in Section 3.4). The primary specification (Column 1) uses application effort, measured by the total number of shifts applied for (with 0 for non-applicants) as the dependent variable. Column 2 reports a maximum likelihood estimation that uses whether or not an individual applied as the dependent variable. The coefficient on Tournament is negative but not significant, indicating that the tournament compensation scheme deters male applicants, but not significantly (Columns

\footnotetext{
${ }^{7}$ Note that since fewer men sign up, there may not be enough power to detect significant effects for men. Therefore, we also report on regressions with treatment dummy-gender interactions later in the paper.
} 
1 and 2). Importantly, the Tournament-Female interaction is negative and significant at the $5 \%$ level. $^{8}$. The results suggest that women exert $14 \%$ less effort than men in applying for competitive relative to flat rate compensation jobs, and are also about 1 percentage point less likely to apply for them.

I have now established that the competitive, performance based compensation schemes deter males somewhat, but that the effect is strong and significant only for women. This brings me to my first result:

Result 1: When the job is described as a performance-based tournament rather than a flat rate compensation scheme, propensity to apply drops, significantly more so for women.

Table 3: Gender Differences in Competitiveness

\begin{tabular}{lcc}
\hline \hline & $(1)$ & $(2)$ \\
& Application Effort & Applied (MLE) \\
\hline Tournament & -0.013 & -0.0020 \\
Bonus & $(0.027)$ & $(0.0019)$ \\
& 0.025 & 0.0011 \\
Female & $(0.031)$ & $(0.0021)$ \\
& $0.19^{* * *}$ & $0.015^{* * *}$ \\
Tourn. x Female & $(0.043)$ & $(0.0028)$ \\
& $-0.14^{* *}$ & $-0.0080^{* *}$ \\
Bonus x Female & $(0.054)$ & $(0.0036)$ \\
& -0.044 & -0.0023 \\
Constant & $(0.061)$ & $(0.0040)$ \\
& $0.083^{* * *}$ & $0.0074^{* * *}$ \\
\hline Observations & $(0.020)$ & $(0.0015)$ \\
\hline \hline
\end{tabular}

Note: OLS with Flat as comparison group. Non-profit excluded. Robust standard errors.

${ }^{*} \mathrm{p}<0.10,{ }^{* *} \mathrm{p}<0.05,{ }^{* * *} \mathrm{p}<0.010$

\subsection{Gender Differences in Risk Preferences}

The Bonus treatment, which is not based on performance but contains an uncertainty in earnings like the Tournament, was designed to identify (1) whether gender differences in risk preferences translate to gender differences in willingness to apply for jobs with uncertain payoffs in the labor market and (2) how much of the gender gap is due to differences in preferences towards uncertain payoffs. In fact, application rates of men

\footnotetext{
${ }^{8}$ An alternative regression to Column 2 is the Logit/Probit; however, interactions in Logit/Probit are biased.
} 
are directionally higher in the Bonus relative to the Flat Rate (by 16\%). On the other hand, the application rates of women are directionally lower in Bonus relative to Flat Rate (by 4.6\%). Neither the comparison of women in Flat Rate to Bonus nor men in Flat rate to Bonus are statistically significant $(p=0.74$ for women and $p=0.59$ for men). These results suggest that uncertainty in payoffs cannot explain the shying away from competition observed among men, and may also not be the main factor deterring women from competing.

When comparing Bonus to the Tournament, both men and women are less likely to apply under the Tournament than the Bonus, a statistically significant result for women $\left(\chi^{2}\right.$ test $\left.p<0.01\right)$ and approaching significance for men $\left(\chi^{2}\right.$ test $\left.p=0.12\right)$. The conclusion holds also when comparing number of shifts selected (Mann-Whitney $p<0.01$ for women but $p=0.12$ for men when comparing Tournament and Bonus.

Evidence that the drop in application rates when the job is described as performance-based is not due solely to differences in risk preferences is obtained through post-estimation tests on the regressions displayed in Table 3. Post-estimation tests comparing the Tournament-Female interaction to the Bonus-Female interaction show statistically significant differences at the $10 \%$ level $(p=0.09$ in Column $1, p=0.11$ in Column 2). Moreover, the coefficients on Bonus and Bonus-Female interaction are not significantly different $(p>0.10)$. Thus, the second major result is:

Result 2: The drop in application rates when the job is described as a performancebased tournament is not due to a difference in preference for uncertainty in payoffs.

The interpretation of Result 2 is that gender differences in risk preferences do not drive the gender gap in competitiveness. The Bonus treatment measures risk preferences directly, without any mention of performance, which avoids any confounds with confidence or ability in the measure. In particular, the worker spins a wheel and receives a bonus with a $50 \%$ probability. The results are in line with Flory et al. (2014), who finds that preferences over uncertainty are not sufficient to explain the gender gap. A major difference is that in Flory et al. (2014) the risk measure includes an ambiguity component (the bonus is earned if the worker's effort ends up contributing to journal article publications). Alternative explanations for the gender gap in this context could be differences in confidence between men and women, with men displaying greater confidence in their ability to receive the bonus under the Tournament compensation scheme. 


\subsection{Impact of Non-Profit on Job Entry Decisions}

I now turn to the question of whether and how the non-profit frame impacts job entry decisions. As noted in section 3.1, there is a positive effect of the Non-Profit treatments on applications. Pooling together both genders, the frame of the non-profit significantly increases the likelihood of applying for the job $\left(\chi^{2}\right.$ test $\left.p=0.06\right)$ and the application effort (Mann-Whitney $p=0.06$ ). There are some differences by compensation scheme. In the Flat Rate, the non-profit frame increases application rates by $10.0 \%$ (women) to $38.5 \%$ (men). In the Tournament, the non-profit frame increases application rates by $47 \%$ (women) to $37 \%$ (men). The increase in application rates and effort is statistically significant in the Tournament $(p=0.03$ both for application likelihood and application effort). This brings me to the next result:

Result 3: Students are more likely to apply for the job when it is described as benefiting a non-profit, and the result is strongest under the Tournament compensation scheme.

Result 3 is suggestive of the theory that at least some individuals have pro-social preferences and receive utility from work that increases the welfare of others., either through 'warm glow' or purely altruistic preferences. Imas (2014), Tonin and Vlassopoulos (2014) and Charness et al. (2014) find that individuals sometimes work harder or more when the benefits accrue to a charity. I find that individuals may also be more willing to apply to a job when benefits accrue to a charity. As far as I am aware, this is the first such finding in the literature.

The finding that the non-profit frame increases applications mostly in the tournament compensation scheme is consistent with a story that competitiveness and prosocial preferences are negatively correlated (as found in the lab experiment of Savikhin and Sheremeta (2013)). Suppose that the most pro-social individuals are deterred by the tournament (since they are least competitive), but not by the flat rate compensation scheme. Then, the non-profit, appealing to pro-social individuals, will most likely increase applicants from the Tournament treatment group (the pro-social individuals were already applying in the Flat Rate treatment group). There is room here for gender differences in willingness to apply, since women who would initially opt out due to being less competitive in the Tournament, may instead choose to enter when the Tournament is couched within the non-profit framing.

The next question is whether the non-profit frame decreases the gender gap in

willingness to compete. Table 4 provides regressions that include all treatments (except for the Bonus) and gender interactions. As before, Column 1 reports on a regression with application effort as the dependent variable, while Column 2 provides a maximum 
likelihood estimation with willingness to apply as the dependent variable. Notice that the Non-profit Tournament Female interaction is smaller than the Tournament-Female interaction in Column 1 - showing that when the non-profit frame is used, women put forth $12 \%$ less effort than men to enter as compared to without the frame, in which case women put forth $14 \%$ less effort than men. The likelihood of choosing to apply is also lower - the coefficient on Tournament-female is -0.008 and significant at the $5 \%$ level in Column 2, but only -0.004 and not statistically significant for the Nonprofit Tournament-Female. However, there are no statistically significant differences between the Tournament-Female and Non-profit Tournament-Female interactions in post-estimation tests ( $p>0.10$ for both Columns 1 and 2). I interpret this result as suggestive evidence that the non-profit frame decreases the gender gap in the willingness to apply to competitive jobs.

More work is needed to understand how pro-social preference differences may be used to overcome the gender gap in competitiveness. The subtle nature of the framing may contribute to the limited improvement in the gender gap. The only difference between the main treatment and the treatment with the non-profit frame was the line in the e-mail, 'the materials for this project are for a charity drive for a non-profit.' If students reading the e-mails were not attentive, they may not have caught on to the frame at all. In addition, working for the university may in itself be a pro-social act (the university is also a non-profit, and helping professors with research may be thought of as pro-social). Hence, the impact of the frame may have been smaller than it would be in a for-profit setting.

In related work, women respond differently than men to social incentives. In particular, when given the choice, women are more likely to sacrifice private compensation to increase social compensation (Tonin and Vlassopoulos, 2014), and women are more responsive than men to elicitations of action-oriented altruism (Tonin and Vlassopoulos, 2010). Women are also more responsive than men to social pressure in charitable giving campaigns DellaVigna, List, Malmendier and Rao (2013).

\subsection{Career Choice and Job Entry Decisions}

Next, I ask whether the gender gap in competitiveness is correlated with major choice, using administrative data on school at the university. I compare students in the College of Letters \& Science, the School of Education, the School of Nursing and the School of Human Ecology, to the more competitive Wisconsin School of Business and the College of Engineering. I also split up the sample by undergraduate or graduate student status. One measure of competitiveness of the schools and colleges is their selectivity. While 
Table 4: Regressions with Non-Profit Frame (Excludes Bonus Treatment)

\begin{tabular}{lcc}
\hline \hline & $(1)$ & $(2)$ \\
& Application Effort & Applied (MLE) \\
\hline Tournament & -0.013 & -0.0020 \\
Flat Charity & $(0.027)$ & $(0.0019)$ \\
Non-profit Tourn. & 0.042 & 0.0029 \\
& $(0.034)$ & $(0.0022)$ \\
Female & 0.023 & -0.0000021 \\
& $(0.034)$ & $(0.0021)$ \\
Tourn. x Female & $0.19^{* * *}$ & $0.015^{* * *}$ \\
& $(0.043)$ & $(0.0028)$ \\
Non-profit Flat x Female & $-0.14^{* *}$ & $-0.0080^{* *}$ \\
Non-profit Tourn. x Female & $(0.054)$ & $(0.0036)$ \\
& -0.053 & 0.00020 \\
Constant & $(0.062)$ & $(0.0042)$ \\
& $-0.12^{* *}$ & -0.0044 \\
Observations & $(0.057)$ & $(0.0039)$ \\
\hline \hline
\end{tabular}

Note: OLS with Flat as comparison group. Bonus excluded. Robust standard errors.

${ }^{*} \mathrm{p}<0.10,{ }^{* *} \mathrm{p}<0.05,{ }^{* * *} \mathrm{p}<0.010$

students can choose most majors in Letters and Science simply by declaring the major, students wishing to enter Business or Engineering programs can only do so through a rigorous application process - that is, being admitted to UW does not guarantee admission to the Business or Engineering programs. For instance, as stated on the admissions website for the Wisconsin School of Business, "admission [...] depends on academic success in college-level course work, standardized testing, and nonacademic strengths such as leadership, involvement and other experiences outside the classroom $[\ldots]$ top candidates [...] offered admission directly from high school." ${ }^{\prime 9}$ Note that while the process to get into Business or Engineering programs is selective, in my sample I also classify students as being in Business or Engineering if they have declared this as their 'pre-major' (prior to selection). Another difference between the programs is the level of math required. While Business and Engineering require 15 to 17 credits of math, statistics or hard sciences, the general education requirements (faced by many majors in Letters \& Science, Nursing, Education and Human Ecology) are only 3-6 credits.

\footnotetext{
${ }^{9}$ See the undergraduate catalogue at pubs.wisc.edu/ug/
} 
Niederle and Vesterlund (2011) found that girls who are more competitive are more likely to select into the science track during secondary school. Indeed, in my sample the undergraduate school with the lowest proportion of women is Engineering (21\%), followed by Business (42\%). Women make up $47 \%$ of all graduate students, and 54\%$77 \%$ of all undergraduate students are in Letters \& Science, Education, Nursing or Human Ecology. Along those lines, one prediction may be that students selecting Business or Engineering majors in my sample may also be more competitive.

Figures 1, 2 and 3 provide a breakdown of application rates by program (the number of e-mails sent by gender is provided at the bottom of each figure). While small sample sizes do not allow me to conduct statistical analysis for each program, a few interesting insights emerge. First, undergraduate women in the Business and Engineering programs seem to embrace competition (application rates of $1.63 \%$ in Flat Rate relative to $1.94 \%$ in Tournament), see Figure 1. Undergraduate women in the Business and Engineering programs are also willing to apply to work under the Bonus compensation scheme (application rate of 2.61\%). Men in the Business and Engineering programs also do not shy away from competition, applying to the Flat Rate $0.61 \%$ of the time and to Tournament $0.85 \%$ of the time (Bonus is $1.33 \%$ ). Second, the job entry decisions of graduate school students mimic the rest of the sample closely (see Figure 2. All of the above suggests that the gender gap is driven by students in the less competitive (and more female-heavy) schools of Letters \& Science, Education, Nursing and Human Ecology (Figure 3).

Table 5 provides regressions on application effort with a dummy variable for Business/Engineering and interaction terms (Letters \& Science and the graduate students are the comparison group). Notice that while students from the Business and Engineering programs are in general less likely to apply for the temporary assistant job, the tournament compensation scheme is actually appealing to these students. The coefficients on Tournament-Business/Engineering and Bonus-Business/Engineering are positive and statistically significant (at the $5 \%$ level in Column 1, and $10 \%$ level in Column 2 for the Bonus-Business/Engineering interaction only). Business and Engineering students exert $14 \%$ and $12 \%$ more effort under the Tournament and Bonus as compared to students from the other programs, respectively. I also do not observe a gender difference among Business and Engineering program students, though one possible reason is small sample size. This brings me to the last result:

Result 4: Willingness to apply for a job under a competitive compensation scheme is mediated by one's major: Business/Engineering students actually prefer the competitive compensation scheme. 
Table 5: Business/Engineering Regressions

\begin{tabular}{lcc}
\hline \hline & $(1)$ & $(2)$ \\
& Application Effort & Applied (MLE) \\
\hline Tournament & -0.046 & $-0.0037^{*}$ \\
Bonus & $(0.031)$ & $(0.0021)$ \\
& -0.019 & -0.0011 \\
Female & $(0.034)$ & $(0.0023)$ \\
& $0.18^{* * *}$ & $0.014^{* * *}$ \\
Business/Engineering & $(0.044)$ & $(0.0029)$ \\
Tourn. x Female & $-0.088^{* *}$ & -0.0031 \\
& $(0.036)$ & $(0.0032)$ \\
Tourn. x Bus/Eng & $-0.12^{* *}$ & $-0.0073^{* *}$ \\
& $(0.054)$ & $(0.0037)$ \\
Bonus x Female & $0.14^{* *}$ & 0.0072 \\
& $(0.063)$ & $(0.0047)$ \\
Bonus x Bus/Eng & -0.0071 & -0.00080 \\
Tourn. x Bus/Eng x Female & $(0.063)$ & $(0.0041)$ \\
Bonus x Bus/Eng x Female & $0.19^{* *}$ & $0.0094^{*}$ \\
& $(0.077)$ & $(0.0054)$ \\
Constant & 0.057 & 0.0042 \\
& $(0.16)$ & $(0.0088)$ \\
\hline Observations & -0.10 & -0.00054 \\
\hline \hline
\end{tabular}

Note: OLS with Flat/LS/grad as comparison group. Non-profit excluded. Robust standard errors.

${ }^{*} \mathrm{p}<0.10,{ }^{* *} \mathrm{p}<0.05,{ }^{* * *} \mathrm{p}<0.010$



Figure 1: Application Rates: Business and Engineering 


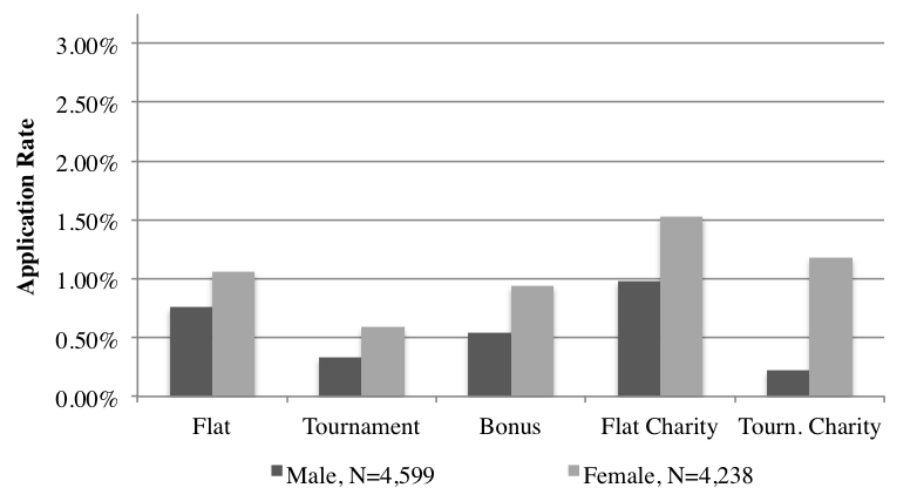

Figure 2: Application Rates: Graduate Students

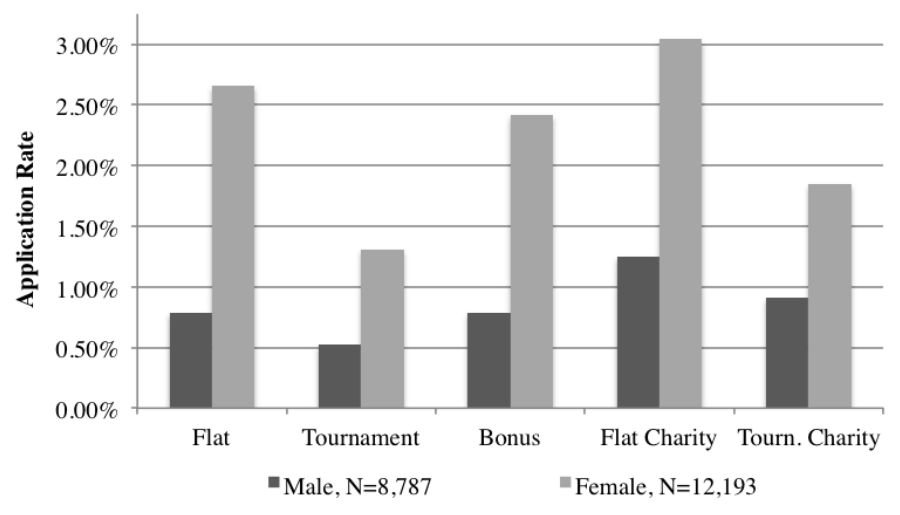

Figure 3: Application Rates: L\&S, Education, Ecology and Nursing

\subsection{Work Performance}

While my workers represent a selected sample, I can also investigate worker performance on the job. Following the job candidate responses, I sent 488 students an e-mail inviting them to work during one of their selected 2-hour shift times. 314 students showed up to work, including 107 in the Flat Rate treatment, 62 in Tournament, 105 in Bonus, 123 in Non-Profit Flat and 91 in Non-Profit Tournament. ${ }^{10}$ Each worker only worked in one shift, under the compensation scheme to which he/she was originally randomized. Once workers arrived, they were all told that they would be helping prepare materials for the charity drive of a non-profit, but their compensation scheme was described as specified in the e-mail they originally received.

Table 6 provides summary statistics on the number of envelopes completed, by treatment and gender (standard errors in parentheses). As expected, the Tournament

\footnotetext{
${ }^{10}$ All students got a standard e-mail inviting them to work and the relatively low show-up rate could be attributed to the fact that we were unable to give each worker their first choice, and we did not allow students to switch from their assigned shifts.
} 
results in a greater number of envelopes completed (106.9) than the Flat Rate (92.5) or the Bonus (91.1), and this difference is statistically significant (Mann-Whitney $p$ values $<0.01$ when comparing Flat Rate or Bonus to Tournament). Interestingly, the difference is strongest among the women - who complete $20.5 \%$ more envelopes in the Tournament relative to the Flat Rate, a statistically significant difference $(p<0.01)$. On the other hand, men complete $13.7 \%$ more envelopes in the Tournament relative to the Flat Rate, a difference that is not statistically significant $(p=0.25){ }^{11}$

Much of the literature on gender differences in competitiveness uses an unselected sample and finds that men increase their effort under competition, while women do not. In this experiment, I find that women do increase their effort under competition, and even do so at greater rates than men. Such a result could be driven by selection (i.e., the most competitive women applied in the Tournament treatment).

I can also investigate whether announcing that the work helps a non-profit affects the productivity of the people who apply. A fairly recent trend in the recruitment strategies of corporations is to provide compensation packages that include a charitable contribution benefit. For instance, Google provides a match for employee charitable contributions. ${ }^{12}$ A possible reason for this trend is to recruit the most productive talent. Note that in my context, since all employees who respond are told that they are helping a non-profit upon arriving to the job, the entire effect of the Non-Profit Flat and NonProfit Tournament treatments on performance should be driven by selection. However, I do not find significant impact of the non-Profit frame on selection (comparisons of Flat Rate to Non-Profit Flat, and Tournament to Non-Profit Tournament, yield MannWhitney $p$-values $>0.10)$.

\section{Discussion \& Conclusion}

Gender differences in preferences have been an active area of research for the past 20 years (Croson and Gneezy, 2009). One of the most economically important insights in this area of work is that women are less competitive than men (Niederle and Vesterlund, 2011). Despite the wealth of laboratory experiments, we know little about how differences in preferences translate to labor markets. In this paper, I investigated the role that gender differences in competitiveness, risk and social preferences play on a real job entry decision. Over 35,000 students at the University of Wisconsin-Madison were invited to apply for a job as a temporary research assistant, without knowing that they

\footnotetext{
${ }^{11}$ However, note that our power to detect differences is substantially smaller among the men, since only 32 men show up in the Flat Rate and Tournament treatments.

${ }^{12}$ See http://www.cbsnews.com/news/google-job-perks-top-10-reasons-we-want-to-work-there/.
} 
Table 6: Work Performance Summary Statistics

\begin{tabular}{|c|c|c|c|c|c|c|}
\hline & \multicolumn{2}{|l|}{ All } & \multicolumn{2}{|c|}{ Females } & \multicolumn{2}{|l|}{ Males } \\
\hline & $\begin{array}{l}\text { Envelopes } \\
\text { Completed }\end{array}$ & $\mathrm{N}$ & $\begin{array}{l}\text { Envelopes } \\
\text { Completed }\end{array}$ & $\mathrm{N}$ & $\begin{array}{l}\text { Envelopes } \\
\text { Completed }\end{array}$ & $\mathrm{N}$ \\
\hline Flat Rate & $\begin{array}{l}92.49 \\
(2.41)\end{array}$ & 79 & $\begin{array}{l}95.97 \\
(2.63)\end{array}$ & 61 & $\begin{array}{l}80.72 \\
(4.86)\end{array}$ & 18 \\
\hline Tournament & $\begin{array}{c}106.88 \\
(4.48)\end{array}$ & 38 & $\begin{array}{c}115.67 \\
(4.59)\end{array}$ & 24 & $\begin{array}{l}91.79 \\
(7.95)\end{array}$ & 14 \\
\hline Bonus & $\begin{array}{l}91.10 \\
(4.49)\end{array}$ & 49 & $\begin{array}{l}98.00 \\
(5.54)\end{array}$ & 35 & $\begin{array}{l}73.86 \\
(5.18)\end{array}$ & 14 \\
\hline $\begin{array}{l}\text { Non-Profit } \\
\text { Flat }\end{array}$ & $\begin{array}{l}89.59 \\
(2.31)\end{array}$ & 90 & $\begin{array}{l}91.16 \\
(2.54)\end{array}$ & 67 & $\begin{array}{l}85.00 \\
(5.21)\end{array}$ & 23 \\
\hline $\begin{array}{l}\text { Non-Profit } \\
\text { Tournament }\end{array}$ & $\begin{array}{l}112.62 \\
(3.82)\end{array}$ & 58 & $\begin{array}{l}116.84 \\
(4.51)\end{array}$ & 43 & $\begin{array}{l}100.53 \\
(6.39)\end{array}$ & 15 \\
\hline
\end{tabular}

were in an experiment. The e-mails soliciting applicants systematically varied (1) the compensation scheme, including a flat rate, performance-based, competitive scheme, and a bonus not based on performance and (2) whether or not the e-mail mentions that the work will help a charity.

I find that competitive, performance based compensation schemes deter workers of both genders from applying, but that the effect is larger and statistically significant for women. This is in line with related work of Flory et al. (2014), who explores the same question using a different, lower educated sample. Interestingly, the decision to apply for a competitive job in my field experiment is correlated with one's major - students from Business and Engineering programs, which are more competitive, do not shy away from competitive compensation schemes. Such a result adds to the work of Buser et al. (2014), who seek to understand how separately elicited competitiveness preferences correlate with the choice of educational track.

Research cites gender differences in risk preferences as a possible mechanism causing the gap in competitiveness. Related work tends to find that women are more risk averse than men (for a summary, see Croson and Gneezy (2009); and for a specific example, see Borghans, Heckman, Golsteyn and Meijers (2009)). I developed a compensation scheme aimed at directly measuring risk preferences over earnings, in which workers received a base payment and were then eligible for a bonus that did not depend on work performance. While I found suggestive evidence of differences in risk preferences (women are directionally more averse to risk than men), differences in aversion to risk were not the main cause of the gap in competitiveness in my experiment. While differences in risk preferences may not cause the gender gap, the question remains as to 
what are the main drivers of the competitiveness gap in this setting. Possible reasons could be greater aversion to compete, receive feedback for performance, or differences in confidence in one's ability to perform the task. Related work in the laboratory shows that gaps in competitiveness or willingness to contribute to a work group can be explained by differences in confidence Charness, Rustichini and van de Ven (2011); Coffman (2014).

In a series of treatments, I also varied whether the job is introduced as a non-profit, a manipulation that may potentially mitigate the effect of the gender gap. Related work finds a significant negative correlation in competitiveness and cooperativeness (e.g., Savikhin and Sheremeta (2013), suggesting that the least competitive individuals may show most concern for others, and may be more likely to respond when the job is described as helping charity. I find that the non-profit manipulation increases application rates overall, and that the result is driven by increased applications under the tournament compensation scheme. This result suggests that for at least some individuals, job market entry decisions are driven by pro-social preferences. The result is also consistent with a story that more competitive individuals are less pro-social and visa versa. More work is needed to learn about the impact of a stronger pro-social manipulation, since results for the gender gap were limited with the subtle manipulation I used in this paper.

A possible concern with the treatments described in this paper is that the Tournament and Bonus compensation schemes may not seem 'natural' to students. If this is the case, students may be deterred from applying not because they have a preference for avoiding uncertain payoffs, but because they do not believe that the job is real. If this were the case, we would observe lower application rates in both the Tournament and Bonus. However, we observe an application rate in the Bonus treatment that is statistically equivalent to the Flat Rate treatment. Moreover, this explanation would not explain the differences we see by gender and major choice.

My results add to our understanding of how economic preferences affect job entry decisions, and their effects on the gender gap in labor market earnings. Together with related work, the results point to the importance of competitiveness preferences, as distinct from risk preferences, in driving labor market decisions. Moreover, the results show a relationship between competitiveness preferences and choice of career path. Finally, this project represents a first step at learning about how job entry decisions are affected by social preferences. 


\section{References}

Andersen, Steffen, Seda Ertac, Uri Gneezy, John A List, and Sandra Maximiano, "Gender, Competitiveness, and Socialization at a Young Age: Evidence From a Matrilineal and a Patriarchal Society," Review of Economics and Statistics, 2013, 95 (4), 1438-1443.

Andreoni, James, "Giving with impure altruism: applications to charity and Ricardian equivalence," The Journal of Political Economy, 1989, pp. 1447-1458.

_ , "Impure altruism and donations to public goods: a theory of warm-glow giving," The Economic Journal, 1990, pp. 464-477.

_ and Lise Vesterlund, "Which is the fair sex? Gender differences in altruism," The Quarterly Journal of Economics, 2001, pp. 293-312.

Balafoutas, Loukas and Matthias Sutter, "Gender, competition and the efficiency of policy interventions," Working Papers in Economics and Statistics, 2010.

Bartling, Björn, Ernst Fehr, Michel André Maréchal, and Daniel Schunk, "Egalitarianism and competitiveness," The American Economic Review, 2009, pp. 93-98.

Ben-Ner, Avner, Fanmin Kong, and Louis Putterman, "Share and share alike? Gender-pairing, personality, and cognitive ability as determinants of giving," Journal of Economic Psychology, 2004, 25 (5), 581-589.

Bertrand, Marianne, "CEOs," Annual Review of Economics, 2009, 1 (1), 121-150.

Blau, Francine D and Lawrence M Kahn, "The gender earnings gap: learning from international comparisons," The American Economic Review, 1992, pp. 533538.

Bolton, Gary E and Elena Katok, "An experimental test for gender differences in beneficent behavior," Economics Letters, 1995, 48 (3), 287-292.

Borghans, Lex, James J Heckman, Bart HH Golsteyn, and Huub Meijers, "Gender differences in risk aversion and ambiguity aversion," Journal of the European Economic Association, 2009, 7 (2-3), 649-658.

Brown, Alexander L, Jonathan Meer, and J Forrest Williams, "Why do people volunteer? An experimental analysis of preferences for time donations," 2013. 
Buser, Thomas, Muriel Niederle, and Hessel Oosterbeek, "Gender, competitiveness and career choices," The Quarterly Journal of Economics, 2014, 1409, 1447.

Cardenas, Juan-Camilo, Anna Dreber, Emma Von Essen, and Eva Ranehill, "Gender differences in competitiveness and risk taking: Comparing children in Colombia and Sweden," Journal of Economic Behavior $\& 3$ Organization, 2012, 83 (1), $11-23$.

Charness, Gary, Aldo Rustichini, and Jeroen van de Ven, "Self-confidence and strategic deterrence," Technical Report, Tinbergen Institute Discussion Paper 2011.

- and Uri Gneezy, "Strong evidence for gender differences in risk taking," Journal of Economic Behavior 83 Organization, 2012, 83 (1), 50-58.

_, Ramon Cobo-Reyes, and Angela Sanchez, "The effect of charitable giving on workers' performance. Experimental evidence," Technical Report, Department of Economic Theory and Economic History of the University of Granada. 2014.

Coffman, Katherine Baldiga, "Evidence on Self-Stereotyping and the Contribution of Ideas," The Quarterly Journal of Economics, 2014, p. qju023.

Croson, Rachel and Uri Gneezy, "Gender differences in preferences," Journal of Economic Literature, 2009, pp. 448-474.

Dargnies, Marie-Pierre, "Men too sometimes shy away from competition: The case of team competition," Management Science, 2012, 58 (11), 1982-2000.

DellaVigna, Stefano, John A List, Ulrike Malmendier, and Gautam Rao, "The Importance of Being Marginal: Gender Differences in Generosity," The American Economic Review, 2013, 103 (3), 586-590.

Dittrich, Marcus, Andreas Knabe, and Kristina Leipold, "Gender differences in experimental wage negotiations," Economic Inquiry, 2014, 52 (2), 862-873.

Eckel, Catherine C and Philip J Grossman, "Are women less selfish than men?: Evidence from dictator experiments," The Economic Journal, 1998, 108 (448), 726735 .

_ and _, "Men, women and risk aversion: Experimental evidence," Handbook of Experimental Economics Results, 2008, 1 (7), 1061-73. 
Einolf, Christopher J, "Gender differences in the correlates of volunteering and charitable giving," Nonprofit and Voluntary Sector Quarterly, 2011, 40 (6), 1092 1112 .

Flory, Jeffrey A, Andreas Leibbrandt, and John A List, "Do Competitive Workplaces Deter Female Workers? A Large-Scale Natural Field Experiment on Job-Entry Decisions," The Review of Economic Studies, 2014.

Gee, Laura, "The More you Know: Information Effects in Job Application Rates by Gender in a Large Field Experiment," Working Paper, 2014.

Gneezy, Uri and Aldo Rustichini, "Gender and competition at a young age," American Economic Review, 2004, pp. 377-381.

_, Kenneth L Leonard, and John A List, "Gender differences in competition: Evidence from a matrilineal and a patriarchal society," Econometrica, 2009, 77 (5), $1637-1664$.

_, Muriel Niederle, and Aldo Rustichini, "Performance in competitive environments: Gender differences," The Quarterly Journal of Economics, 2003, 118 (3), 1049-1074.

Harrison, Glenn W and John A List, "Field Experiments," Journal of Economic Literature, 2004, 42 (4), 1009-1055.

Healy, Andrew and Jennifer Pate, "Can Teams Help to Close the Gender Competition Gap?," The Economic Journal, 2011, 121 (555), 1192-1204.

Imas, Alex, "Working for the "warm glow": On the benefits and limits of prosocial incentives," Journal of Public Economics, 2014, 114, 14-18.

Kuhn, Peter and Marie-Claire Villeval, "Do women prefer a co-operative work environment?," Working Paper, 2011.

Lavy, Victor, "Gender Differences in Market Competitiveness in a Real Workplace: Evidence from Performance-based Pay Tournaments among Teachers," The Economic Journal, 2013, 123 (569), 540-573.

Leibbrandt, Andreas and John A List, "Do women avoid salary negotiations? Evidence from a large-scale natural field experiment," Management Science, 2014. 
Niederle, Muriel and Lise Vesterlund, "Do Women Shy Away From Competition? Do Men Compete Too Much?," The Quarterly Journal of Economics, 2007, 122 (3), $1067-1101$.

_ and _, "Gender and competition," Annual Review of Economics, 2011, 3 (1), 601-630.

_, Carmit Segal, and Lise Vesterlund, "How costly is diversity? Affirmative action in light of gender differences in competitiveness," Management Science, 2013, $59(1), 1-16$.

Samak, Anya, "Is there a gender gap in preschoolers' competitiveness? An experiment in the US," Journal of Economic Behavior \&3 Organization, 2013, 92, 22-31.

Savikhin, Anya and Roman M Sheremeta, "Simultaneous decision-making in competitive and cooperative environments," Economic Inquiry, 2013, 51 (2), 13111323.

Sutter, Matthias and Daniela Glätzle-Rützler, "Gender differences in the willingness to compete emerge early in life and persist," Management Science, 2014.

Tonin, Mirco and Michael Vlassopoulos, "Disentangling the sources of pro-socially motivated effort: A field experiment," Journal of Public Economics, 2010, 94 (11), 1086-1092.

_ and _ , "Corporate Philanthropy and Productivity: Evidence from an Online Real Effort Experiment," 2014.

Waldfogel, Jane, "Understanding the 'family gap' in pay for women with children," The Journal of Economic Perspectives, 1998, pp. 137-156.

Wozniak, David, William Harbaugh, and Ulrich Mayr, "Choices about competition: Differences by gender and hormonal fluctuations, and the role of relative performance feedback," Working Paper, 2009. 


\section{Appendix: For Online Publication}

\section{A E-mail Scripts}

Dear student,

We are seeking temporary student help in the next two weeks to assist with preparing materials for several projects that need to be completed before the end of the semester. Students can sign up to work one 2-hour shift. Many time slots - day, evening and weekend - are available to fit your schedule.

FLAT RATE The materials for this project are very important. So, we will pay you $\$ 24$ for your shift. You will receive your payment right after your shift.

TOURNAMENT The materials for this project are very important. So, we will pay you $\$ 18$ for your shift, with a chance of a bonus of $\$ 12$, which depends on your performance. At the end of your shift, we will compare your work to that of another new worker - the one of you who did the job better will receive the bonus. You will receive your payment right after your shift ( $\$ 30$ if you do better and get the bonus, or $\$ 18$ if you don't).

BONUS The materials for this project are very important. So, we will pay you $\$ 18$ for your shift, with the chance of a bonus of $\$ 12$, which does not depend on how well you do. At the end of your shift, you will spin our bonus wheel with $50 \%$ chance of getting the bonus. You will receive your payment right after your shift $(\$ 30$ if you get the bonus, or $\$ 18$ if you don't).

NON-PROFIT FLAT RATE The materials for this project are for a charity drive for a non-profit and are very important. So, we will pay you $\$ 24$ for your shift. You will receive your payment right after your shift.

NON-PROFIT TOURNAMENT The materials for this project are for a charity drive for a non-profit and are very important. So, we will pay you $\$ 18$ for your shift, with a chance of a bonus of $\$ 12$, which depends on your performance. At the end of your shift, we will compare your work to that of another new worker - the one of you who did the job better will receive the bonus. You will receive your payment right after your shift ( $\$ 30$ if you do better and get the bonus, or $\$ 18$ if you don't). 
While special training is not required, students working for us should be reliable and be quick learners. After a quick (10 minute) training, you will work on preparing materials for the charity drive on your own for the remainder of your shift.

You will do the work on campus at 1300 Linden Drive.

If you would like to apply for this job, please respond with the following information:

1. Your major and year at university 2. Number of course credits you are currently taking 3. Shift(s) you are available, ranked by preference (use date and shift number). THE MORE SHIFTS YOU SELECT, THE MORE LIKELY WE WILL BE ABLE TO FIND YOU A TIME SLOT TO WORK. See below for available shifts. You can work up to one shift.

Please be sure to include your name in your response.

The shifts available are:

- [ LIST OF SHIFTS HERE ]

We hope you consider applying.

Chris Gibbs

Project Assistant

UW-Madison 